\title{
Seismic and earthquake engineering studies in the Arabian plate and the surrounding region
}

\author{
Issa El-Hussain ${ }^{1} \cdot$ Ahmed Deif $^{1} \cdot$ Rengin Gok ${ }^{2} \cdot$ Keith Nakanishi $^{2}$ \\ Published online: 8 September 2021 \\ (C) Saudi Society for Geosciences 2021
}

This special issue covers recent research in seismology and earthquake engineering in the region in and around the Arabian Peninsula and focuses on selected contributions presented at the "10th Gulf Seismic Forum" held at Sultan Qaboos University, 19-22 March 2018. Research topics include seismology, earthquake engineering, seismic and tsunami hazard mitigation, tectonics, and geophysical research in the Arabian Peninsula Region. Seismic activity recorded by networks both within and adjacent to the Arabian Plate shows high concentration of earthquakes along the Arabian Plate boundaries; examples include the Zagros Fold-Thrust Belt, the Dead Sea Fault, and Makran Subduction Zone. This pattern is strongly evident by recent and historic devastating earthquakes that claimed the lives of many hundreds to thousands of people. Examples of those still resonate in our minds, such as the Dhamar Earthquake in Yemen, 1980, the Aqaba Earthquake, 1995, the Bam Earthquake in Iran, 2003, and the Iraq-Iran Border, 2017. The Arabian Peninsula is the focus of vast real-estate development plans and ambitious large-scale projects throughout the region. This special issue will help mitigate the earthquake's hazard and the risk to the vast development plans

This article is part of the Topical Collection on Seismic and Earthquake Engineering Studies in the Arabian Plate and the Surrounding Region

Responsible Editor: Issa El-Hussain

Issa El-Hussain

elhussain@squ.edu.om

Ahmed Deif

adeif@squ.edu.om

Rengin Gok

gok1@1lnl.gov

Keith Nakanishi

keith.nakanishi@gmail.com

1 Sultan Qaboos University, Muscat, Sultanate of Oman

2 Lawrence Livermore Natl. Lab., Livermore, CA, USA and ambitious projects in the region. It fosters stronger cooperation ties between academics and professional individuals and institutions centered in the Arabian Gulf. The issue theme includes but is not limited to the following research topics: (1) seismology and active tectonics; (2) seismic networks: data processing and analysis; (3) seismic hazard, risk, and mitigation; (4) structural and earthquake engineering, and (5) tsunami hazard assessments.

\section{About the associate editors}

Dr. El-Hussain graduated in Geophysics from Damascus University (1981) followed by a M.Sc. Geology (1986) from Wichita State University (USA) and a Ph.D. degree (1991) in Geophysics from Northern Illinois University (USA). He worked as a consultant geophysicist until 1998 and joined the Faculty Geosciences Department at Southeast Missouri State University 1998 to 2002. Dr. El-Hussain joined Sultan Qaboos University as a Fulbright scholar in 2002 and then continued as the director of Earthquake Monitoring Center. He has implemented several research projects including one on seismic hazard assessment for entire Oman. He has co-published more than 40 papers in leading international journals and supervised several M.Sc. students in Geophysics as well as Geosciences. His research interests are wide including shallow geophysical exploration, environmental, earthquake, and tsunami hazard assessments.

Prof. Ahmed Deif is the head of seismic research, studies, and awareness section at Earthquake Monitoring Center, Sultan Qaboos University (SQU). He completed his studies at Cairo University and worked for the last 12 years in SQU. He specializes in the area of seismic hazard assessment and helps his colleagues to conduct such studies, including defining the seismic sources, calculating recurrence parameters, estimating seismic waves attenuation, and using different applications and software. He has collaborated actively with researchers in several other disciplines of seismology. 
Ahmed has served on some conference and workshop program committees at SQU. Ahmed Deif wrote many scientific papers in reputable magazines among his activities including providing training courses in seismology, participating in hazard related consulting, and writing articles in newspapers.

Dr. Rengin Gok is the Program Manager for Seismic Cooperation Program at Lawrence Livermore National Laboratory. She is managing Seismic Cooperation Program for international seismic engagement in the Middle East, Central Asia, Southeast Asia, and the Caucasus region; builds partner capacity for Comprehensive Test Ban Treaty implementation; and develops models for seismic monitoring and seismic hazard assessment.

Dr. Keith Nakanishi is a retired seismologist from the Lawrence Livermore National Laboratory. He received his Ph.D. in Geophysics and Space Physics from the University of California, Los Angeles (UCLA) from which he also received an M.S. in Planetary and Space Physics. His undergraduate degree, A.B., is from Occidental College in Los Angeles in Physics. His interests and experience include long-period seismic waves, earth tides, regional seismology and networks, as well as computational seismology and synthetic seismograms. He has also worked on projects dealing with the monitoring and verification of nuclear test limitation treaties.

The following papers that contribute to the theme of the issue are published in this issue:

1. Seismic monitoring and high-frequency noise using arrays in the Arabian Peninsula

Moira L. Pyle, Rengin Gök, Abdullah Al-Amri, Issa El-Hussain, \& Yasir Al-Rawahi

The study utilizes a time-domain beam-packing method to examine the performance of the arrays in terms of slowness, azimuthal bias, and event detection capabilities. The study finds that the arrays provide slowness vectors with biases comparable with similar-sized arrays in other locations around the world. Arrays also detected regional events of magnitude 3.0 and above most of the time. Strong noise generation that influence event detection capabilities is found in the directions of the Northern Arabian Gulf and Southern Red Sea.

2. Probability of magnitude detection for the seismological network of Oman

Issa El-Hussain, Mohamed Ezzelarab, Mahmoud Sami Suleiman, Ahmed Deif, \&Adel Mohamed El-Shahat Mohamed

This study utilizes the spatial configuration of the seismic network in addition to the recorded phases and the applied magnitude equation to evaluate the probability of magnitude detection. The analysis is done based on a unified magnitude earthquake database for all recorded events for certain time period. Then, synthesized maps of the detection probability of an event with specific magnitude were developed. It also showed the need for additional seismic stations to enhance the detectability of small natural earthquakes.

3. Improved lithospheric attenuation structure of the Arabian Peninsula through the use of national network data

Michael E. Pasyanos, Yahya M. Tarabulsi, Salah Y. Al-Hadidy, Wael W. Raddadi, Abdullah D. Mousa, Issa El-Hussain, Farah Al-Jeri, Haydar Al-Shukri, Rengin Gök

The study characterizes the attenuation structure of the Arabian Peninsula through the measurement of regional phase amplitudes. The result is an improved attenuation model of the crust and upper mantle for a broad frequency band that extends from 0.5 to $10 \mathrm{~Hz}$. The resulting attenuation model can be employed for better magnitude estimates, in isolating tectonic and structural features, and in characterizing strong ground motion in the Arabian Peninsula.

4. Site-specific deterministic and probabilistic tsunami hazard assessment for Diba-Oman and Diba-Al-Emirates

Issa El-Hussain, Zaid Al-Habsi, Khalid Al Bloushi, Rachid Omira, Ahmed Deif, Maria Ana Baptista, \& Adel M. E. Mohamad

In this study, deterministic and probabilistic tsunami hazard assessments are performed for the coasts of Diba-Oman and Diba-UAE, which are located on the western coast of the Oman Sea. The study focuses on earthquake-induced tsunamis. The maximum credible earthquakes from the active segments of Makran Subduction Zone are utilized as specific scenarios for the deterministic approach. The results provided maximum tsunami inundation distance and maximum flow depths due to maximum credible earthquakes. This study provided an uncertainty treated probability of exceedance that a maximum wave height exceeds certain value in 500 years.

5. Study of the 24 September 2013 Oman Sea tsunami using linear shallow water inversion

Maria Ana Baptista, Jorge Miguel Miranda, Rachid Omira, \& Issa El-Hussain

In this study, an undersea landslide tsunami source triggered by inland earthquake is defined utilizing waveform inversion. The study suggests the existence of local tsunami amplifications in a number of Omani harbors. The results also strengthen the hypothesis that landslides might have played an important role in previous tsunami events in the area and must be taken into account for tsunami hazard assessment on the Omani coast.

6. Deaggregation of probabilistic seismic hazard for selected cities in the Arabian Peninsula

Yousuf Al-Shijbi, Ahmed Deif, Issa El-Hussain, Adel M. E. Mohamed, \& Amna Al-Dairi 
The probabilistic seismic hazard assessment results deaggregated for 26 cities in the Arabian Peninsula based on equal spacing in magnitude and distance for the amplitudes of PGA, spectral accelerations at $2 \%$ and $10 \%$ probability of exceedance in 50 years in order to determine which earthquake source contributes most to the hazard. The study shows that seismic hazard at cities close to major active tectonic structures are influenced mostly by earthquakes at nearby distances for both return periods for all considered spectral periods. For cities far away from the major tectonic elements, the seismic hazard is generally controlled by remote larger earthquakes for long spectral periods and by nearby small to moderate events for shorter ones.

7. Updating a probabilistic seismic hazard model for Sultanate of Oman

Ahmed Deif, Issa El-Hussain, Yousuf Alshijbi, Adel M.E. Mohamed

In this study, the probabilistic seismic hazard assessment for the Sultanate of Oman is revised using an updated homogeneous earthquake catalogue, recent seismic source model, and more recent and applicable ground-motion prediction equations. Seismic hazard maps in terms of horizontal peak ground acceleration and 5\% damped spectral accelerations at the bedrock conditions were generated for the important population centers.

8. Evaluation of Saudi National Seismic Network (SNSN) detectability

M. Sami Soliman, Hani M. Zahran, Salah Y. Elhadidy, \& Wael W. Alraddadi

This is the first detailed study of earthquake detection capabilities of the Saudi National Seismic Network (SNSN). The study shows that the network in recent time period has greater ability to detect and locate earthquakes occurred in the western part of Saudi Arabia and lesser detection ability in the middle and southern part of Saudi Arabia. The study conclude that the SNSN with its current status is capable to detect all events occurred inside the Saudi Arabia and its surroundings, except the Rub' al Khali region, because it has no seismic stations installed.

9. Seismic source characterization of the Arabian Peninsula and Zagros Mountains from regional moment tensor and coda envelopes

Andrea Chiang, Rengin Gök, Yahya M Tarabulsi, Salah Y El-Hadidy, Wael W Raddadi, \& Abdullah D Mousa

The study uses time-domain full waveform moment tensor inversion and coda envelope-derived amplitude measurements to solve for earthquake source mechanism, moment magnitudes, and their source type. Authors proved the efficiency of this method to provide accurate source parameters. Earthquake source mechanism and moment magnitude are invaluable information in the assessment of seismic hazard, plate motions, and the characterization of faults and regional stress field.

\section{Declarations}

Conflict of interest The authors declare that they have no competing interests. 